\title{
Influence of Packaging and Storage Conditions on the Volatile Composition of Selected Greek Red Wines
}

\author{
Christina I. Piperidi ${ }^{1}$, George Vlahavas ${ }^{2}$, Panagiotis G. Demertzis ${ }^{1}$ and \\ Konstantoula Akrida-Demertzi ${ }^{1}$ * \\ ${ }^{1}$ Laboratory of Food Chemistry, Department of Chemistry, University of Ioannina, P.O. Box 1186, GR-45110 \\ Ioannina, Greece. \\ ${ }^{2}$ Department of Food Technology, Alexandrian Technological Educational Institution of Thessaloniki, PO Box \\ 14561, GR-57400 Thessaloniki, Greece
}

*Corresponding author: E-mail: kakrida@uoi.gr (K. Akrida-Demertzi)

\begin{abstract}
The volatile composition is a very important factor affecting the wine aromatic attributes and hence its quality. In the present study, the influence of packaging (glass and virgin PET bottles) and storage conditions (for 12 months under cellar and refrigeration temperature) on the composition of the major volatile constituents of two types of Greek red wines produced in the areas of Leucada ("Vertzami") and Zante ("Avgoustiatis") were evaluated. A liquid/liquid extraction method was applied for the isolation of the studied compounds. The identification of the volatile compounds was performed by GC/MS and the quantitative determination by GC/FID analysis. Obtained data were evaluated applying techniques of multivariate statistical analysis (Cluster and Principal Component Analysis). Cluster analysis was performed to group the wine varieties and storage times. Principal Component Analysis showed that the first two components explained $92.5 \%$ of the total variation. The prevailing volatile compounds for the first principal component were ethyl octanoate, isobutanol, ethyl acetate, 1-propanol, 1-hexanol, ethyl lactate, amyl alcohols and 1-pentanol, while for the second principal component these were furfural, acetaldehyde and 2-phenylethanol. Using ANOVA on the resulting principal components it was found that wine variety and storage time are statistically significant factors for all three principal components, while packaging material, storage temperature and all possible factor interactions were not. These results suggest that the use of virgin PET bottles could be an alternative to package wine during a short period of time (6-12 months).
\end{abstract}

Keywords: Cluster and Principal Component Analysis, GC/MS and GC/FID analysis, Greek red wines, liquid/liquid extraction, packaging, volatile composition,

\section{Introduction}

Wine is a sensitive and complex combination that is formed by hundreds of compounds. One of the most important characteristics influencing wine quality and consumer preferences is its aroma determined by the volatile fraction of wine. More than 1000 aromatic compounds have been identified in the wine volatile fraction, originating from different chemical groups, such as higher alcohols, aldehydes, ethyl esters of fatty acids, fatty acids, ketones, monoterpenes and volatile phenols. Some volatile compounds originate from the grapes, but most of them are formed from the modification caused during grape must processing (yeast strain, fermentation conditions, winemaking practices), wine aging and storage conditions [1-3].

Moreover the influence of the wine volatile compounds on the final aroma depends on their concentration and the specific perception threshold of each compound $[4,5]$. But if a wine is not stored and transported under the proper conditions required, its volatile composition will not maintain its optimal state, due to chemical degradation [6,7]. Several volatile compounds have been reported as oxidation products or oxidation-related compounds in different wines. These compounds can be related to one of the following aspects: 1) decrease in the concentrations of monoterpene alcohols, 2) formation of substances from carbohydrate degradation, 3) changes in the ester content (decrease in acetates and increase in mono- and dicarboxylic acid ethyl esters) and 4) formation of unwanted products $[8,9]$.

The packaging of wine requires special attention. The most suitable container for packaging wine is glass. Several investigators studied the chemical changes due to different packaging (glass bottles and PET bottles with and without oxygen scavenger). In the normal PET bottles they observed larger changes than in the glass bottles due to significant changes in enological parameters, anthocyanin fraction, volatiles, and sensory properties. They concluded that glass containers should be preferred for bottling wine, being the only material with a high impermeability to gases and vapors, stability in time, transparency and readily recycled [3, 10-12].

"Vertzami" is one of the most richly red colour Greek grape varieties, cultivated mostly in the island of Leucada. It is considered relative variety with the Marzemino or Barzamino of Venice. The produced wine has madder colour and it is used mainly for the production of wines mixed with other grape varieties [13].In the 
island of Zante the "Avgoustiatis" Greek red vinification variety is cultivated and used to produce a red wine with intense color $[13,14]$.

In this work, a combined solvent extraction-GC/FID method for the quantitative analysis of the major volatile constituents of two types of Greek red wines produced in the areas of Leucada ("Vertzami") and Zante ("Avgoustiatis") is reported, during their storage under cellar and refrigeration temperature conditions for a period of 12 months in two types of containers (glass and PET). Identification of compounds was accomplished by GC/MS analysis. Dichloromethane was used to extract the volatiles and the extracts were subjected to GC analysis without further concentration [15]. Obtained data were evaluated applying techniques of multivariate statistical analysis (Cluster and Principal Component and Analysis).

\subsection{Wine samples, chemicals and reagents}

\section{Materials And Methods}

The wine samples were from 2005 vintage and were bottled in 2006 . The fermentation temperature was $18{ }^{\circ} \mathrm{C}$. Samples were stored in a cellar (with temperature ranged from $12{ }^{\circ} \mathrm{C}$ to $16{ }^{\circ} \mathrm{C}$ ) and in refrigeration in two types of containers (glass and virgin PET bottles) and analyzed at specific time intervals (0, 3, 6, 9 and 12 months). Measurements were carried out in triplicate. The storage time was taken to be the time elapsed from the exact date of bottling to the date of analysis. High purity chromatographic standards, substances and solvents were obtained from Merck and Aldrich (Germany). All reagents were used without further purification.

\subsection{Liquid/liquid extraction}

A liquid/liquid extraction method was applied for the extraction of the volatile compounds of the wine samples: wine $(100 \mathrm{ml}), \mathrm{CH}_{2} \mathrm{Cl}_{2}(10 \mathrm{ml})$ as extraction agent, $1 \mathrm{ml}$ of 2-octanol solution $\left(72.04 \mathrm{mg} / \mathrm{lin} \mathrm{CH}_{2} \mathrm{Cl}_{2}\right)$ as internal standard and sodium chloride $(20 \mathrm{~g})$ to reduce the degree of emulsification at the wine/ $\mathrm{CH}_{2} \mathrm{Cl}_{2}$ interface, were added in a 300ml-flask. The flask was cooled in melting ice and the wine/ $\mathrm{CH}_{2} \mathrm{Cl}_{2}$ mixture was stirred at $200 \mathrm{rpm}$ for $2 \mathrm{~h}$. The wine $/ \mathrm{CH}_{2} \mathrm{Cl}_{2}$ emulsion formed during stirring was separated from the aqueous layer and frozen at $-20{ }^{\circ} \mathrm{C}$. The flask was then allowed to reach room temperature, and the $\mathrm{CH}_{2} \mathrm{Cl}_{2}$ layer, progressively separated from the remaining wine, was transferred without concentration into screw-capped vial and stored at $-20{ }^{\circ} \mathrm{C}$ for further GC/FID and GC/MS analysis [15].

\subsection{Synthetic wine and recovery tests}

A model wine solution was prepared composed of tartaric acid at $6.5 \mathrm{~g} / \mathrm{L}$ in $11.5 \%$ (v/v) aqueous ethanol. The synthetic working standard solution was prepared by dissolving appropriate amounts of each of the volatile compounds listed in Table 1 in the model wine solution. This solution was used to evaluate the extraction recovery of the flavor compounds [16-18]. Recovery tests were performed by extraction of the synthetic working standard solution according to the proposed method.

\subsection{GC/FID and GC/MS analysis of volatiles.}

The GC unit was a Fisons 9000 series gas chromatograph equipped with a flame ionization detector (FID). The separation column was $30 \mathrm{~m}$ long X $0.32 \mathrm{~mm}$ internal diameter fused silica DB-Wax capillary (J\&W Scientific) with film thickness of $0.25 \mu \mathrm{m}$. The following GC parameters were kept constant: detector temperature, $240{ }^{\circ} \mathrm{C}$; injector temperature, $200{ }^{\circ} \mathrm{C}$; carrier gas $(\mathrm{He})$ flow rate, $1.5 \mathrm{ml} / \mathrm{min}$; injection mode split with split ratio 1:50; injection volume $2 \mu$. The applied column temperature program was $40^{\circ} \mathrm{C}(7 \mathrm{~min})$, from $40{ }^{\circ} \mathrm{C}$, at a rate of $15{ }^{\circ} \mathrm{C} / \mathrm{min}$, to $160{ }^{\circ} \mathrm{C}(1 \mathrm{~min})$ and from $160{ }^{\circ} \mathrm{C}$, at a rate of $30{ }^{\circ} \mathrm{C} / \mathrm{min}$, to $230{ }^{\circ} \mathrm{C}(5 \mathrm{~min})$. Calibration curves for GC quantification were constructed by dissolving known amounts of the flavor compounds, including internal standard (2-octanol), in aqueous ethanol solution having alcohol content similar to that of the analyzed wines. The GC/MS system consisted of a Hewlett-Packard 6890 (Wilmington, DE, USA) gas chromatograph coupled to an HP-5973 mass selective detector. The GC was equipped with a DB-Wax capillary column. The GC conditions were the same as above. The transfer line was held at $260{ }^{\circ} \mathrm{C}$. Ionization was carried out with electron energy of $70 \mathrm{eV}$. Identification of compounds was accomplished by comparing retention times and mass spectra (SCAN mode, 28-550 amu) with those of reference standards using the GC/MS Willey 275L workstation.

\subsection{Statistical analysis}

Cluster analysis (Ward linkage method, correlation coefficient) was performed on the data in order to group the wine varieties and storage times. Principal Component Analysis (PCA) was applied to determine which volatile compounds contribute to the variability between wine varieties, storage times, storage temperature and packaging material. ANOVA was finally used on the resulting principal components to determine if they are influenced significantly by these factors. 


\section{Results And Discussion}

Thirty compounds were detected in the characteristic volatile profile of wine samples. Most of them participate in the configuration of the aroma of the wine. Figure 1 shows a representative GC/MS chromatogram.

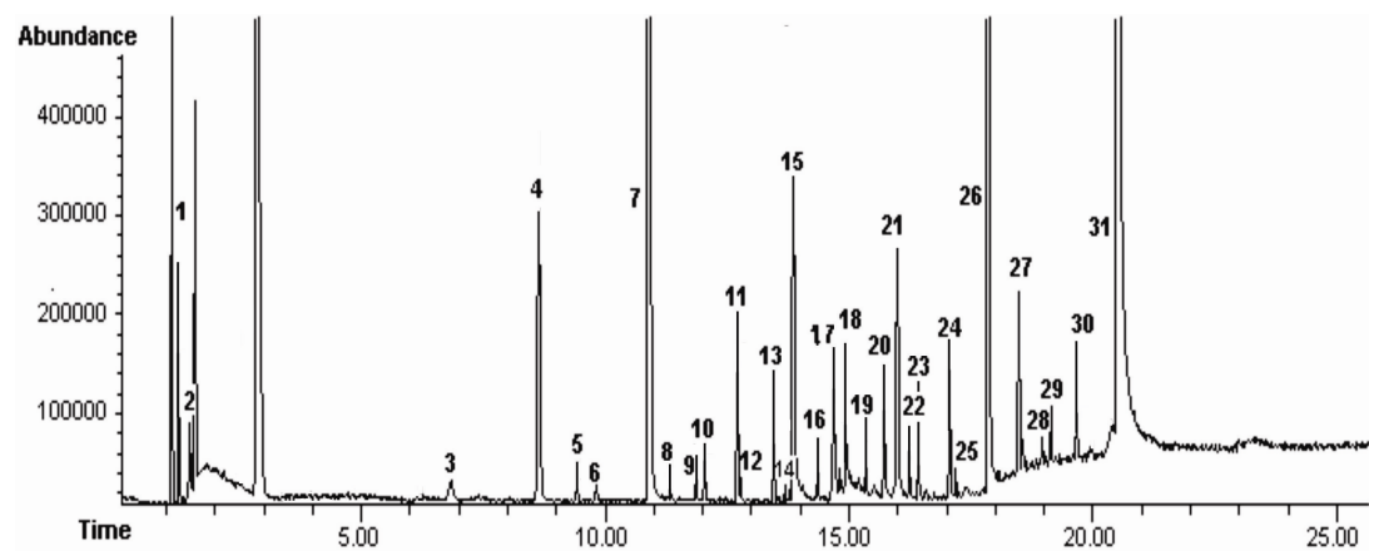

Figure 1. GC/MS chromatogram of red wine "Avgoustiatis" stored in glass container for 12 months. (1) acetaldehyde, (2) ethyl acetate, (3) 1-propanol, (4) isobutanol, (5) isoamyl acetate, (6) 1-butanol, (7) amyl alcohols, (8) ethyl hexanoate, (9) 1-pentanol, (10) 3-hydroxybutanone or acetoin, (11) ethyl lactate, (12) 1hexanol, (13) ethyl octanoate, (14) furfural, (15) acetic acid, (16) L-linalol, (17) 2-octanol (I.S.), (18) 2, 3butanediol, (19) butanoic acid, (20) y-butyrolactone, (21) butanedioic acid, (22) a-terpineol, (23) 2methylthiopropanol or methionol, (24) 4-hydroxy-ethylbutanoate, (25) hexanoic acid, (26) 2-phenylethanol, (27) benzyl alcohol, (28) octanoic acid, (29) decanoic acid, (30) ethyl decanoate, (31) monoethyl succinate.

The major volatile compounds, which were determined quantitatively in both wine varieties and their concentration range are given in Table 1. The cited concentration ranges are the average of at least three measurements. The relative recovery (RR) values for liquid/liquid extraction of flavor compounds ranged from 93.20 to $99.65 \%$ and are generally comparable to those reported by other investigators [16, 17, 19].

Alcohols are the main volatile compounds in many wine varieties. 1-propanol has fruity and alcoholic aromas and could be important aroma compound for fermented drinks. Higher alcohols can have an aromatic effect in wines and some higher alcohols can be considered positive and others can be considered negative to the aromatic profile of wine. However, due to the concentration that is found in wines and its high threshold, higher alcohols do not have remarkable sensory effects in wine. Excessive concentrations of some alcohols other than ethanol may cause off-flavors, sometimes described as "spicy", "hot", or "solvent-like".2-phenylethanol is an alcohol with a pleasant floral odor that occurs widely in nature. It is responsible for honey-like aromas, a major aroma component of Muscat wine [20]. Ethyl acetate is the most common ester in wine, being the product of the most common volatile organic acid- acetic acid, and the ethyl alcohol generated during the fermentation. The aroma of ethyl acetate is most vivid in younger wines and contributes towards the general perception of "fruitiness" in the wine. Ethyl octanoate is an aroma active compound and is mainly responsible for the aroma of various juices and wines. Ethyl lactate is found naturally in small quantities in a wide variety of foods including wine, chicken, and various fruits. The odor of ethyl lactate when dilute is mild, buttery and creamy, with hints of fruit and coconut [21].

Table 1. Major volatile compounds quantified in both wine varieties and their concentration range

\begin{tabular}{|c|c|c|}
\hline Volatile compound & \multicolumn{2}{|c|}{ Concentration range (mg/L) } \\
\hline & Vertzami & Avgoustiatis \\
\hline Acetaldehyde & $4.72-12.97$ & $0.69-14.69$ \\
\hline Ethyl acetate & $25.70-47.30$ & $2.50-12.40$ \\
\hline 1-Propanol & $14.54-28.88$ & $43.44-52.84$ \\
\hline Isobutanol & $19.40-21.63$ & $24.48-29.00$ \\
\hline Amyl alcohols & $154.41-166.24$ & $261.48-297.18$ \\
\hline 1-Pentanol & $0.52-0.88$ & $0.16-1.86$ \\
\hline Ethyl lactate & $26.18-40.47$ & $273.14-478.03$ \\
\hline 1-Hexanol & $6.88-12.31$ & $7.94-18.05$ \\
\hline Ethyl octanoate & $11.04-28.81$ & $21.16-44.48$ \\
\hline Furfural & $18.50-36.39$ & $13.34-28.67$ \\
\hline 2-Octanol (I.S) & & $203.50-368.74$ \\
\hline 2-Phenylethanol & $188.06-381.71$ & \\
\hline I.S: internal standard & & \\
\hline
\end{tabular}


Acetaldehyde is the principal aldehyde present in wine. As wine ages, acetaldehyde levels increase due to chemical oxidation of ethanol. Normal acetaldehyde concentration in newly fermented table wines is $<75$ $\mathrm{mg} / \mathrm{L}$. At elevated levels, the presence of acetaldehyde is not desirable in table wines giving them an overoxidized character. Furfural is reported to contribute to the aroma of wines and distillates with dried nut tones. Its content usually increases during aging of wines and distillates [22]

Cluster analysis (Fig. 2) showed that wines from the two varieties are completely different concerning their volatile compounds. The composition of "Vertzami" wines changes significantly over the first three months of storage and after six months until nine months of storage, while "Avgoustiatis" wines' composition changes significantly after three months and until the sixth month of storage.

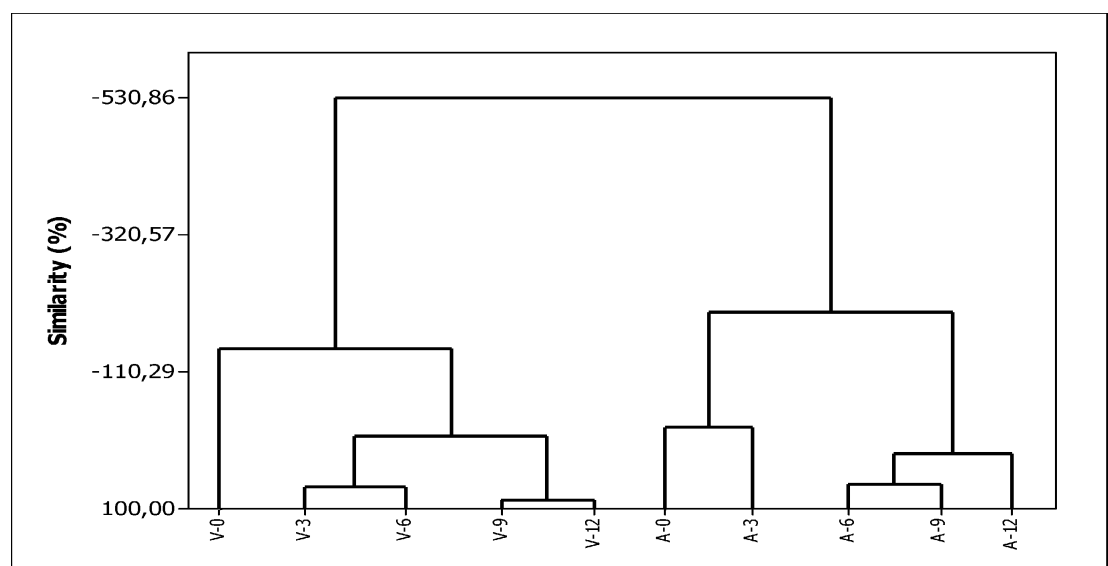

Figure 2. Cluster analysis dendrogram (Ward linkage, correlation coefficient). V=Vertzami, A=Avgoustiatis, 0 3-6-9-12: Storage time (months)

Principal Component Analysis results showed that the first two components explained $92.5 \%$ of the total variation (Table 2). The prevailing volatile compounds for the first principal component were ethyl octanoate, isobutanol, ethyl acetate, 1-propanol, 1-hexanol, ethyl lactate, amyl alcohols and 1-pentanol, while for the second principal component these were furfural, acetaldehyde and 2-phenylethanol.

Table 2. Loading factors for the first three principal components

\begin{tabular}{lccc}
\hline Volatile compounds & PC1 & PC2 & PC3 \\
\hline 1-Hexanol & 0,911 & $-0,306$ & 0,070 \\
1-Pentanol & 0,781 & $-0,444$ & 0,426 \\
1-Propanol & 0,921 & 0,350 & $-0,150$ \\
2-Phenylethanol & 0,550 & $-0,751$ & $-0,225$ \\
Acetaldehyde & 0,393 & $-0,872$ & 0,056 \\
Amyl alcohols & 0,864 & 0,489 & $-0,010$ \\
Ethyl acetate & $-0,921$ & $-0,272$ & 0,268 \\
Ethyl lactate & 0,906 & 0,385 & 0,104 \\
Ethyl octanoate & 0,966 & $-0,245$ & $-0,041$ \\
Furfural & $-0,004$ & $-0,911$ & $-0,171$ \\
Isobutanol & 0,953 & 0,284 & 0,045 \\
\hline Variance & $63.7 \%$ & $28.8 \%$ & $3.4 \%$ \\
\hline
\end{tabular}

From the loading plot between the first two principal components (Fig. 3) and the corresponding score plot for wine varieties (Fig. 4) it can be concluded that the two wine types are significantly different. "Vertzami" wines exhibit higher concentrations of ethyl acetate while "Avgoustiatis" wines show higher concentrations of amyl alcohols, ethyl lactate, 1-propanol and isobutanol. 


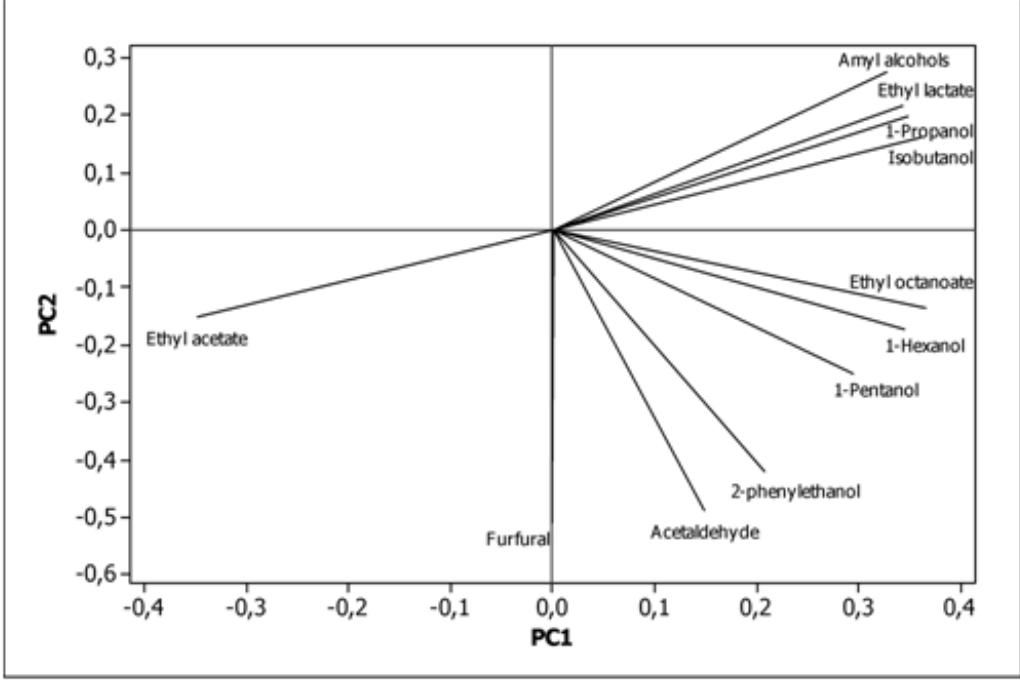

Figure 3. Loading plot for the first two principal components

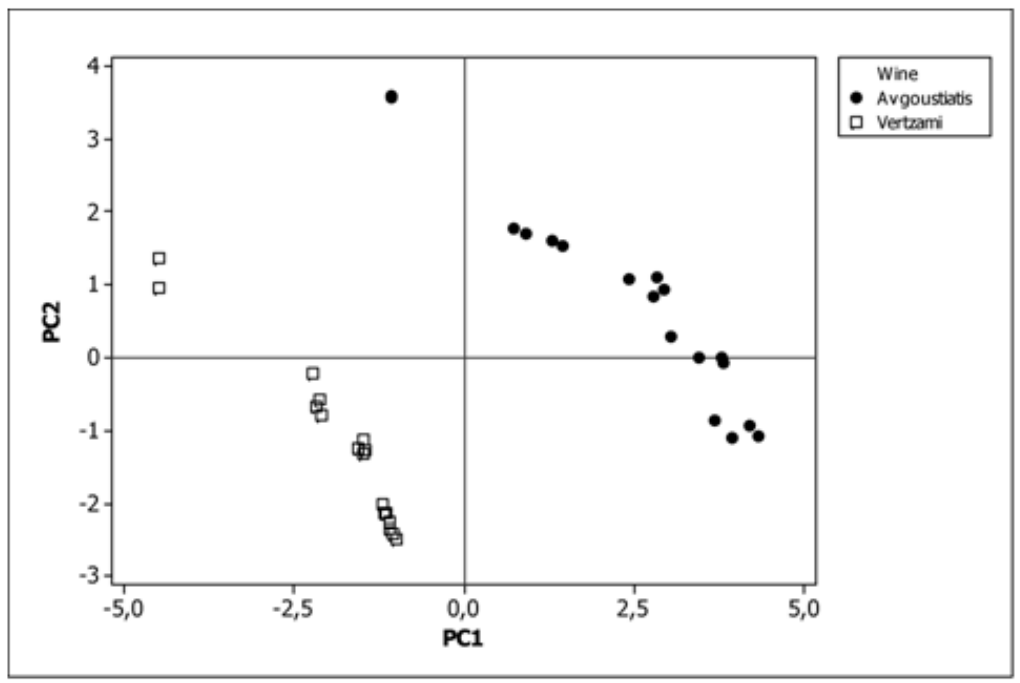

Figure 4. Score plot between the first two principal components categorized by wine variety

The score plot for storage time (Fig. 5), when examined together with the loading plot (Fig. 3), shows that with increasing storage time 1-pentanol, 2-phenylethanol, 1-hexanol, acetaldehyde, ethyl octanoate and furfural concentrations are also increasing for both wine varieties.

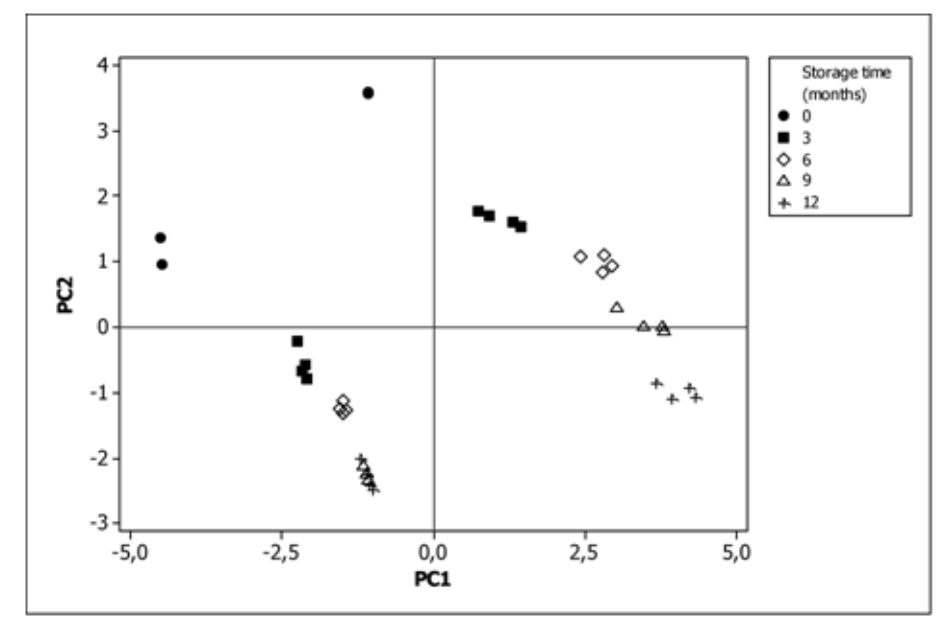

Figure 5. Score plot between the first two principal components categorized by storage time 
Performing 4-way ANOVA on the resulting first two principal components, shows that wine variety and storage time are significant factors $(\mathrm{P}<0.05)$ while packaging material and storage temperature are not $(\mathrm{P}>0.05)$. Main effects plots for all examined factors for each of the first two principal components are shown in Figures 6 and 7. All interaction terms were proven to be not significant for both of the first two principal components $(\mathrm{P}>0.05)$. These results lead to the conclusion that the use of virgin PET bottles could be an alternative to package wine during a relatively short period of time (6-12 months) and are in general accordance with those of other investigators [23, 24].

"Avgoustiatis" wines show higher values for the first two principal components compared to "Vertzami" wines. So, "Avgoustiatis" wines have significantly higher concentrations of ethyl octanoate, isobutanol, 1-propanol, 1-hexanol, ethyl lactate, amyl alcohols and 1-pentanol and lower concentrations of ethyl acetate than "Vertzami" wines.

The first principal component increases, while the second principal component decreases significantly with storage time. Therefore, furfural, acetaldehyde and 2-phenylethanol concentrations increase significantly with storage time.

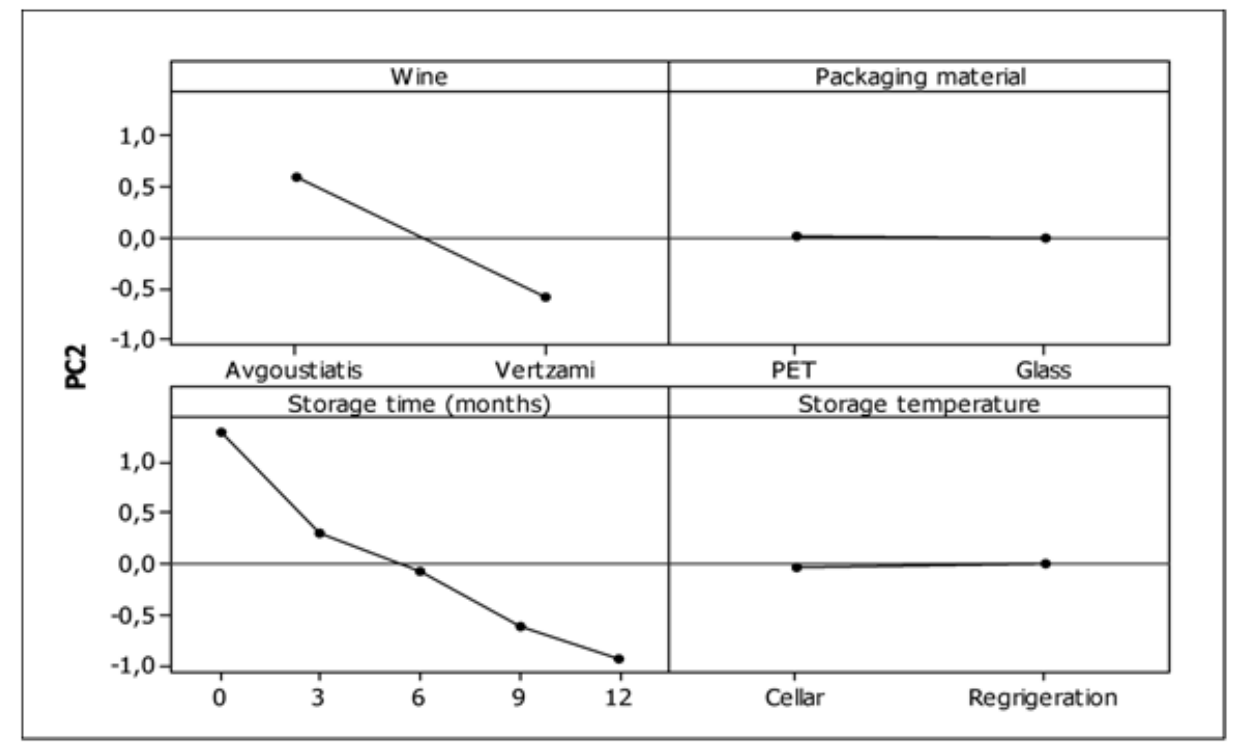

Figure 6. Main effects plot for the first principal component

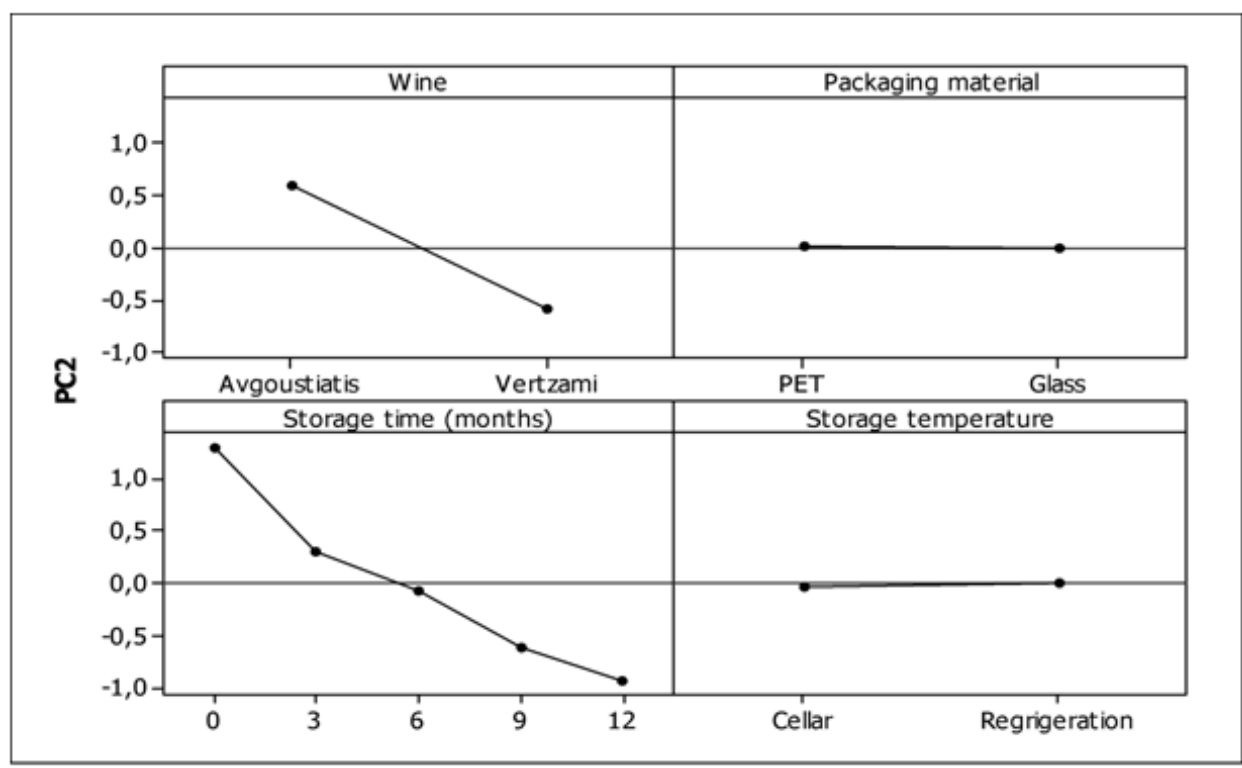

Figure 7. Main effects plot for the second principal component 


\section{Acknowledgements}

The access on the GC/MS facilities of the Food Quality Certification Unit of the University of Ioannina is gratefully acknowledged. Thanks are also due to the "Agro Corporation TAOL Leukada" for providing "Vertzami" wine and to the company "Dionisis Sidirokastritis S.A." in Zante for providing "Avgoustiatis" wine.

\section{References}

[1] Pérez -Prieto, L.J., López-Roca, J.M., and Gómez-Plaza E. (2003). Differences in major volatile compounds of red wines according to storage length and storage conditions. Journal of Food Composition and Analysis, 16, 697-705.

[2] Andujar-Ortiz, I., Moreno-Arribas, M.V., Martín-Álvarez, P.J., and Pozo-Bayón, M.A. (2009). Analytical performance of three commonly used extraction methods for the gas chromatography-mass spectrometry analysis of wine volatile compounds. Journal of Chromatography A, 1216, 7351-7357.

[3] Moreira N., Lopes P., Ferreira H., Cabral M., Guedes de Pinho P. (2016) Influence of packaging and aging on the red wine volatile composition and sensory attributes, Food Packaging and Shelf Life, 8, 14-23.

[4] Falqué E., Fernàndez P. and Doubourdieu D. (2001). Differentiation of white wines by their aromatic index. Talanta, 54, $271-281$.

[5] Welke J. E., Zanus M., Lazzarotto M. and Alcaraz Zini C. (2014). Quantitative analysis of headspace volatile compounds using comprehensive two-dimensional gas chromatography and their contribution to the aroma of Chardonnay wine. Food Research International, 59, 85-99.

[6] Boulton R.B., Singleton V. L., Bisson L. F. and Kunkee R.E. Principles and practises of winemaking. (New York, Boston, London, Chapman and Hall, 1998).

[7] Scrimgeour N., Nordestgaard S., Lloyd N.D.R. and Wilkes E.N. (2015). Exploring the effect of elevated storage temperature on wine composition. Australian Journal of Grape and Wine Research, 21, 713-722.

[8] Recamales A. F., Gallo V., Hernanz D., Gonzàlez-Miret M. L. and Heredia F. J. (2011). Effect of time and storage conditions on major volatile compounds of Zalema white wine. Journal of Food Quality, 34, 100-110.

[9] Hopfer H., Buffon P. A., Ebeler S. E. and Heymann H. (2013). The Combined effects of storage temperature and packaging on the sensory, chemical, and physical properties of a Cabernet Sauvignon wine. Journal of Agricultural and Food Chemistry, 1-15.

[10] Gonzalez-Viñas M. A., Pérez-Coello M. S., Salvator M. D., Cabezudo M. D. and Martin-Alvarez P. J. (1996). Changes in gas chromatographic volatiles of young Airen wines during bottle storage. Food Chemistry, 56, 4, 399-403.

[11] Bathe P. Developments in the packaging of alcoholic drinks. (Pira International, Surrey, UK, 1997).

[12] Mentana A., Pati S., La Notte E. and del Nobile M. A. (2009). Chemical changes in Apulia table wines as affected by plastic packages. LWT - Food Science and Technology, 42, 1360-1366.

[13] Galet P. Dictionnaire encyclopédique des cépages. Hachette livre (Hachette practique, 2000).

[14] Soufleros, E. (1997). Soufleros E. Enology, Science and Know How (in Greek). (Vol I and II, , Thessaloniki, Greece, 2010).

[15] Pricer C., Etievant P. X., Kicklaus S. and Brun O. (1997). Representative Champagne wine extracts for gas chromatography oflactometry analysis. Journal of Agricultural and Food Chemistry, 45, 3511-3514.

[16] Ferreira V., Rapp A., Cacho J. F., Hastrich H. and Yavas I. (1993). Fast and quantitative determination of wine flavour compounds using microextraction with freon-13. Journal of Agricultural and Food Chemistry, 41, 1413-1420.

[17] Zhou Y., Riesen, R. and Gilpin C. S. (1996). Comparison of Amberlity XAD-2/Freon 11 extraction with liquid/liquid extraction for the determination of wine flavour components. Journal of Agricultural and Food Chemistry, 44, 818-822.

[18] Gallo V., Beltran R., Heredia F. J., Gonzàlez-Miret M. L. and Hernanz D. (2011). Application of multivariate statistical analyses to the study of factors affecting white wine volatile composition. Journal of Food Quality, 34, 40-50.

[19] Ortega C., Lopez R., Cacho J. and Ferreira V. (2001). Fast analysis of important wine volatile compounds. Development and validation of a new method based on gas chromatography-flame ionization detection analysis of dichloromethane microextracts. Journal of Chromatography A, 923, 205-216.

[20] Bakker J.and Clarke R. J. Wine: Flavour Chemistry, (Blackwell Publishing Ltd, Oxford, UK, 2012).

[21] Hornsey I. The Chemistry and Biology of Winemaking, (RSC Publishing, Cambridge, UK, 2007).

[22] Zoecklein B., Fugelsang K. C., Gump B.and Nur F. S., Wine Analysis and Production, (Aspen Publishers, N.Y., 1999).

[23] Dombre C., Marais S., Chappey C., Lixon-Buquet C.and Chalier P. (2014). The behaviour of wine aroma compounds related to structure and barrier properties of virgin, recycled and active PET membranes, Journal of Membrane Science, 463, $215-225$.

[24] Dombre C., Rigou P., Wirth J.and Chalier P. (2015). Aromatic evolution of wine packed in virgin and recycled PET bottles, Food Chemistry, 176, 376-387. 